\title{
Electroosmotic Zeta Potential Measurements on Single Crystals
}

\author{
WILLEM SMI'T AND HANS N. STEIN \\ Laboralory of General Chemistry, Eindhoven University of Technology, Eindhoven, The Netherlands
}

Received April 30, 1976; accepted September 10, 1976

\begin{abstract}
A technique by which the $\zeta$ potential of rodlike materials can be measured is described. The electroosmosis of the system consisting of a rod placed in a cylindrical hole drilled in a piece of PTFE is measured. The method was tested with vitreous silica. The isoelectric point of a synthetic sapphire, grown by the Tyco EFG process, was situated at pH 3.3. The $\zeta$ potential of PTFE, required in the calculation, was measured similarly on a rod of PTFE. The method can be applied to any material in which a cylindrical hole can be drilled and from which an appropriate rod can be formed; the method can be applied also to materials from which only rodlike pieces are available.
\end{abstract}

\section{INTRODUCTION}

If one wants to connect the colloid chemical properties of solids with their solid-state parameters and surface properties, one meets the difficulty that the electrokinetic measurements need crushing of the solids, by which the characteristics of the surface are lost. In the case of $\mathrm{ZnO}$ single crystals f.i., the electrical conductivity and the color of the solid change on crushing. We therefore investigated the possibility of measuring the electrokinetic potential on rodlike crystals.

The method we developed was tested on cylindrical rods of vitreous silica (fused quartz), of which the $\zeta$ potential in dependence on the $\mathrm{pH}$ is known, measured in a capillary (1) as well as on powders (2) at constant concentrations of background electrolyte, $\mathrm{KNO}_{3}$ and $\mathrm{NaCl}$, respectively.

In order to demonstrate the potentialities of the method, measurements were also performed on a sapphire $\left(\alpha-\mathrm{Al}_{2} \mathrm{O}_{3}\right.$ single crystal) grown with the $c$ axis parallel to the geometric axis by the Tyco E.F.G process (3).

The essence of the method is that one measures the electroosmosis of a system consisting of a rod placed in a cylindrical hole in a piece of a suitable material f.i. polytetrafluoroethylene
(PTFE). The method requires knowledge of the $\zeta$ potential of the material used as wall material for the hole. It is measured in an analogous manner on a rod of the material substituted for the crystal. This shows at the same time that the $\zeta$ potential of any material in which a cylindrical hole can be drilled and from which an appropriate rod can be formed can be measured by the present technique.

\section{THEORETICAL BACKGROUND}

The rod (radius $r$ ) whose $\zeta$ potential is to be measured is placed in a cylindrical hole (radius $R$, length $l$ ) in a piece of PTFE, with both ends protruding. A potential difference $V$ is applied across the hole. The displacement of the liquid under the influence of the applied field can be observed in two horizontal precision bore tubes (radius $r_{m}$ ). The electrokinetic potential $\zeta$ can be calculated from this displacement with a modified Helmholtz-Smoluchowski equation, which can be derived as follows. In the case of an axial-symmetrical position of the rod in the hole the differential equation appropriate to the system is

$$
d\left[\eta \rho \frac{d v(\rho)}{d \rho}\right]-\epsilon_{0} \epsilon_{r} \frac{V}{L} d\left[\rho \frac{d \psi(\rho)}{d \rho}\right]=0 .
$$


This follows from the balance between the electrical and frictional forces upon a layer of liquid between two coaxial cylindrical surfaces in the stationary state (compare (4)), with the use of the Poisson equation in cylindrical coordinates. In this differential equation $v(\rho)$ is the velocity of the liquid in the axial direction on a distance $\rho$ from the axis, $\eta$ is the viscosity, $\epsilon_{0}$ is the permittivity of free space, $\epsilon_{r}$ is the dielectric constant, and $\psi(\rho)$ is the potential distribution in the equilibrium double layer and is taken as zero in the center of the liquid. When the distance between the solid surface and the slipping plane is denoted by $\delta$, the slipping planes $(v=0)$ are located at $\rho=r+\delta$ $\left(\psi=\zeta_{1}\right)$ and $\rho=R-\delta\left(\psi=\zeta_{2}\right)$.

Integration of [1] between these slipping planes yields

$$
\begin{aligned}
v(\rho)= & \frac{\epsilon_{0} \epsilon_{r}}{\eta} \frac{V}{L}\left(\psi-\zeta_{1}\right) \\
& \quad+\frac{\epsilon_{0} \epsilon_{r}}{\eta} \frac{V}{L}\left(\zeta_{1}-\zeta_{2}\right) \frac{\ln r-\ln \rho}{\ln r-\ln R} .
\end{aligned}
$$

The volume of liquid passing per second through a cross section of the annular capillary is given by

$$
\begin{aligned}
D= & \int_{r+\delta}^{R-\delta} v(\rho) 2 \pi \rho d \rho \\
= & \frac{\pi \epsilon_{0} \epsilon_{r}}{\eta} \frac{V}{L}\left\{\left(\frac{R^{2}-r^{2}}{2(\ln R-\ln r)}-r^{2}\right) \zeta_{1}\right. \\
& \left.\quad+\left(R^{2}-\frac{R^{2}-r^{2}}{2(\ln R-\ln r)}\right) \zeta_{2}\right\}
\end{aligned}
$$

if we neglect the term

$$
\frac{2 \pi \epsilon_{0} \epsilon_{r}}{\eta} \frac{V}{L} \int_{r+\delta}^{k-\delta} \psi \rho d \rho,
$$

which is permissible as long as the thickness of the layers where $\psi$ differs appreciably from zero is small with respect to $R-r$ [at $I=0.001 M, 6 \times(1 / \kappa) \approx 5 \times 10^{-6} \mathrm{~cm}$, where $\kappa$ is the Debye-Hückel reciprocal distance].
In [3], $\zeta_{1}$ and $\zeta_{2}$ have the sign of the electrode to which the liquid close to the wall concerned is streaming.

Relation [3] is also used in the nonaxial position of the rod (see the Appendix for a justification). In this case there are regions in which the thickness of the layers where $\psi$ differs appreciably from zero is of the same order as the space between the surfaces of the hole and of the rod, but a correction term as in [3] is still negligible for reasons similar to those which make the contributions to $D$ of the other terms in these regions negligible. The condition that $D$ be equal to the volume passing per second through a cross section of the measuring capillaries ( $\mathrm{J}$ in Fig. 1) yields the relation

$$
\zeta_{1}=\left(\frac{l r_{m}^{2} \eta}{t} \frac{L}{\epsilon_{0} \epsilon_{r}} \frac{L}{V} A-\zeta_{2} B\right) K,
$$

in which $l$ is the displacement of the menisci in the measuring capillaries in $t \mathrm{sec}$ and

$$
\begin{aligned}
& A=\left\{\frac{R^{2}-r^{2}}{2(\ln R-\ln r)}-r^{2}\right\}^{-1}, \\
& B=A\left\{R^{2}-\frac{R^{2}-r^{2}}{2(\ln R-\ln r)}\right\} .
\end{aligned}
$$

The factor $K$ accounts for the fact that $D$ is lowered by the factor $1 /(1+n)$ when the hydrodynamic resistance of the hole with an annular cross section in $P$ (Fig. 1 ) is $1 / n$ of the sum of those of the measuring capillaries (4-6). $K$ is given by

$$
K=1+\frac{l_{1}+l_{2}}{L}\left(\frac{R_{\mathrm{eff}}}{r_{m}}\right)^{4} \frac{\eta_{m}}{\eta},
$$

where $\left(l_{1}+l_{2}\right)$ is the total length of the liquid threads in the measuring capillaries (viscosity of the liquid $\eta_{m}$ ) and $R_{\text {eff }}$ is the effective radius of the space between rod and plug. The effective radius is obtained by putting the resistance against the flow of the space between rod and plug equal to that of a cylindrical capillary:

$$
R_{\mathrm{eff}}=\left\{\frac{\left(R^{2}-r^{2}\right)^{2}}{\ln r-\ln R}-r^{4}+R^{4}\right\}^{\frac{1}{4}} .
$$




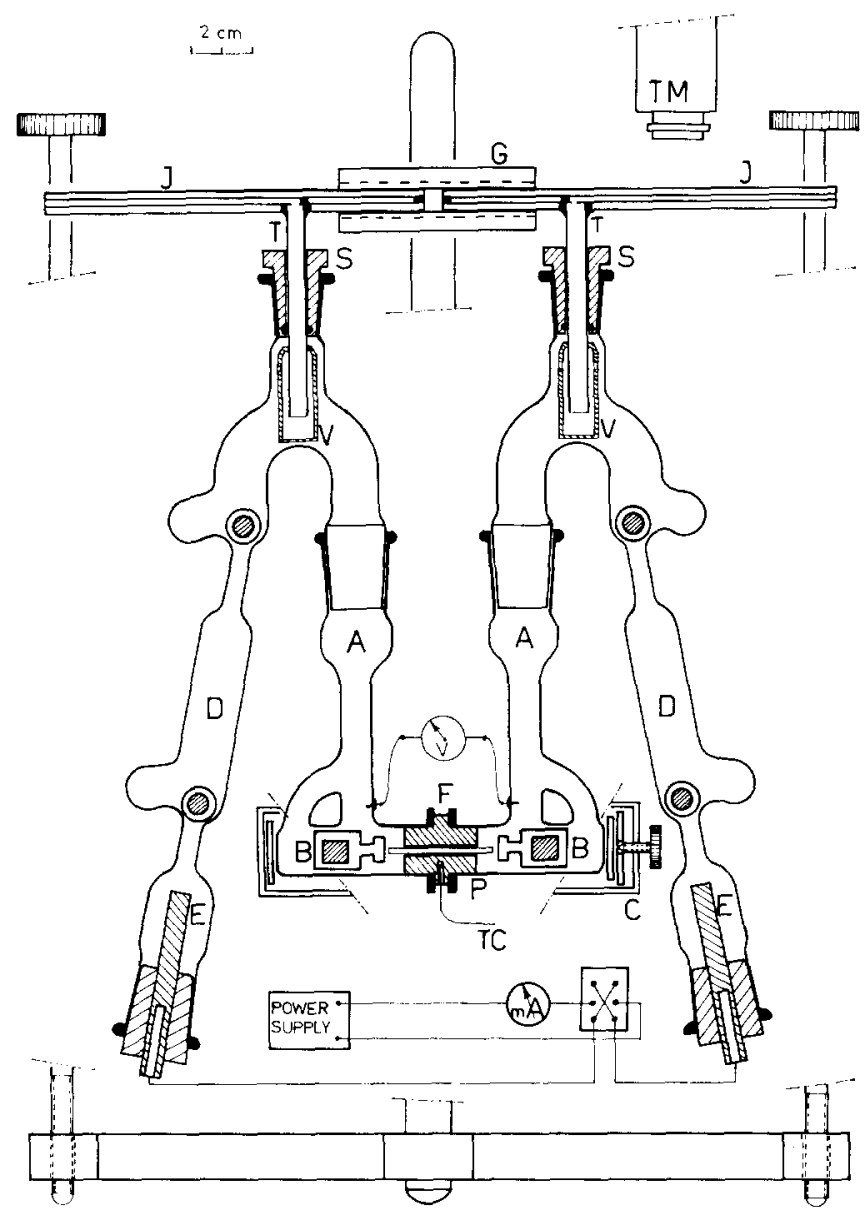

Fig. 1. Apparatus used for the electroosmosis measurements.

Table I gives the values of $R_{\text {eff }}, K, B$, and $A$, calculated for $R=0.110 \mathrm{~cm}$ with a varying radius $r . K=1+n$ has been calculated with $l_{1}+l_{2}=10 \mathrm{~cm} ; L=2 \mathrm{~cm} ; r_{m}=0.08 \mathrm{~cm}$, and $\eta_{m} / \eta=1$. In this table the $K$ value in the case with the rod omitted is also given. With increasing $R-r$ the electroosmotic flow decreases and in the limiting case with no rod in the hole this flow is only about $5 \%$ of that calculated by von Smoluchowski's formula. Thus, although $\zeta_{2}$ can in principle be determined by omitting the rod in the hole, this measurement would be impractical, especially when $\zeta_{2}$ is small.

Therefore, we measured $\zeta_{2}$ with a rod of the same material in the hole. In this case $\zeta_{1}$ and $\zeta_{2}$ are supposed to be equal and $\zeta_{2}$ can be solved from [4]. Table I shows that $A$ is much more dependent on $R-r$ than $B$. Each percentage of uncertainty in $R-r$ causes an uncertainty of about $1 \%$ in $A$ and about $0.1 \%$ in $B$. Thus, the method requires an accurate determination of $R$ and $r$.

\section{EXPERIMENTAL}

Electroosmosis apparatus. The electroosmosis apparatus is shown schematically in Fig. 1. A PTFE cylindrical body $\mathrm{P}$, the middle section of which has a larger outer diameter than its ends and in which an axial cylindrical hole has been drilled, is clamped between flanges $\mathrm{F}$ in the middle part AFA of the Pyrex glass apparatus (clamp C). The rod for which the 
TABLE I

$K, B$, and $A$ Values, Calculated for $R=0.110 \mathrm{~cm}$ and Varying $r$

\begin{tabular}{ccccc}
\hline $\begin{array}{c}r \\
(\mathrm{~cm})\end{array}$ & $\begin{array}{c}B_{\text {erf }} \\
(\mathrm{cm})\end{array}$ & $K^{a}$ & $R$ & $\begin{array}{c}A \\
\left(\mathrm{~cm}^{-2}\right)\end{array}$ \\
\hline 0.1000 & 0.0193 & 1.017 & 1.066 & 984 \\
0.0998 & 0.0197 & 1.018 & 1.067 & 966 \\
0.0996 & 0.0199 & 1.019 & 1.068 & 949 \\
0.0990 & 0.0208 & 1.023 & 1.079 & 902 \\
0.090 & 0.0321 & 1.130 & 1.143 & 536 \\
0.080 & 0.0430 & 1.418 & 1.236 & 392 \\
0.070 & 0.0527 & 1.941 & 1.349 & 326 \\
0.060 & 0.0614 & 2.739 & 1.491 & 293 \\
- & 0.110 & 18.872 & - & - \\
\hline
\end{tabular}

${ }^{a} K=1+n$ calculated with $l_{1}+l_{\mathrm{s}}=10 \mathrm{~cm}, L=2$ $\mathrm{cm}, r_{m}=0.08 \mathrm{~cm}$, and $\eta_{m} / \eta=1$.

$\zeta$ potential is to be measured is placed in the hole. By means of glass bodies B with iron cores, situated on both sides of the PTFE cylinder, the rod can be kept in place when the apparatus is filled. The nongassing electrodes $\mathrm{E}$ (zinc rods in saturated zinc sulfate solution) are separated from the liquid in the central part by compartments $\mathrm{D}$ filled with $0.5 \mathrm{M}$ $\mathrm{KNO}_{3}(7)$. To avoid leakages glass balls with iron cores, instead of taps, are used, to prevent the mixing of the liquids. The measurements can be performed with the balls in the closed position; but when necessary they can be removed by means of a magnet.

The displacement of the liquid is observed in two Jena glass precision bore capillaries $\mathrm{J}$ $\left(r_{m}=0.80 \mathrm{~mm}\right)$. Pyrex tubes $\mathrm{T}$ are cemented perpendicularly on these capillaries at flatground and perforated parts. The shorter parts of the capillaries are stopped with PTFE and lute. The capillaries are connected to the rest of the apparatus through holes with O-ring seals in PTFE stoppers S. Small PTFE vessels $\mathrm{V}$ are clamped under these stoppers on the protruding tubes $T$. The vessels are provided with holes at the tops of their side walls. The purpose of these vessels is to prevent the liquid from the capillaries, to which a detergent is added (see below), from falling down to the rod in the PTFE body $\mathrm{P}$, because of its greater density. With a clamp $G$, provided with bars with a V-groove on its jaws, both capillaries are exactly aligned. The apparatus is clamped on a tripod and located beside a table on which a traveling microscope TM (Hilger-Watts) is mounted in a horizontal plane. Both adjusting screws of the tripod have been lengthened to a height well above the table.

The electroosmosis current is taken from a dc power supply and is applied to the electrodes via a polarity reversal switch, which can also be actuated every 5 or $10 \mathrm{sec}$ by means of an electronic flip-flop circuit. With a pair of blank platinum wire electrodes, fixed close to the PTFE body $P$, and a digital dc voltage meter (Tekelec TA 310-06) the potential across the hole in $\mathrm{P}$ is measured. With a copperconstantan thermocouple, fixed in a hole in the flange of the PTFE body $\mathrm{P}$ near to the axial hole, the temperature in the PTFE cylinder is measured. From experiments in which a second thermocouple was fixed in a PTFE rod in the axial hole, the difference between the inner and outer thermocouple readings was obtained as a function of the power dissipated in the PTFE cylinder.

Samples. The following samples were used in the experiments.

(i) Vitreous silica (fused quartz), Herasil I (10-50 ppm Al, reported by the manufacturer), two rods, $d=0.1988 \mathrm{~cm}$.

(ii) Sapphire ( $\alpha-\mathrm{Al}_{2} \mathrm{O}_{3}$ single crystal), grown with the $c$ axis parallel to the geometric axis by the Tyco edge-defined, film-fed growth (EFG) method (3). This method is a crystal-pulling technique in which melt from a reservoir is drawn by capillary action to the tip of a die from which growth takes place. The form of the growing crystal is determined by the shape of the die surface.

The crystal, obtained from Tyco, Saphikon Division, was an as-grown rod. Thus, the crystal has not been shaped by cutting, grinding into a rod, and flame polishing. The cross section of the crystal was not exactly circular. After chemical polishing (see the next section) the mean of measurements of the diameter with a micrometer at six axial positions in five 
directions $(6 \times 5$ measurements $)$ was $d$ $=0.1369 \mathrm{~cm}$ (the extreme values of the individual measurements were 0.1360 and $0.1390 \mathrm{~cm}$ ).

(iii) PTFE cylinders in which holes with diameter and length of 0.2210 and $2.10 \mathrm{~cm}$, respectively, in case (i) and of 0.1600 and 2.20 $\mathrm{cm}$, respectively, in case (ii) were drilled. The diameters of the PTFE rods were (i) 0.2026 and (ii) $0.1380 \mathrm{~cm}$.

Chemicals. The $\mathrm{NaCl}$ used was of analytical grade. All the solutions used had a $10^{-3} \mathrm{M} \mathrm{NaCl}$ background. A $0.1 N \mathrm{HCl}$ solution was used for $\mathrm{pH}$ adjustment. All water used (conductivity $<0.7 \times 10^{-6} \mathrm{ohm}^{-1} \mathrm{~cm}^{-1}$ ) was triply distilled, the second stage being from alkaline permanganate.

\section{Purification Procedures}

Samples (i). Two rods, each $6 \mathrm{~cm}$ long, were treated with $45 \% \mathrm{HF}$ at room temperature during $20 \mathrm{~min}$ with rotation. After washing with water the rods were stored until use in distilled water. The various steps in measuring the $\zeta$ potential were: (a) wiping with dry filter paper, (b) cleaning in condensing vapor of carbon tetrachloride for $30-45 \mathrm{~min}$ (8), (c) flaming in a colorless Bunsen burner flame (8), (d) immersing in 5\% $\mathrm{HF}$ for $10 \mathrm{~min}$, (e) washing with water and wiping with filter paper, (f) cleaning in condensing vapor of carbon tetrachloride, (g) flaming and cooling, (h) equilibrating the solution to be measured in a weighing bottle for at least $20 \mathrm{hr}$. In half of experiments steps c, d, e, and f were omitted.

Samples (ii). A common EFG phenomenon is an array of microvoids $50 \mu \mathrm{m}$ below the surface (3). We, therefore, treated a piece of length $3 \mathrm{~cm}$ with phosphoric acid of about $340^{\circ} \mathrm{C}(9)$ with rotation of the crystal. After $2 \times 25 \mathrm{~min}, 0.012 \mathrm{~g}$ was etched away, corresponding to $23 \mu \mathrm{m}$ if the etching were uniform; however, etch pits had been formed scattered over the surface. After its washing with water, the crystal was stored overnight in an $\mathrm{NaOH}$ solution $(\mathrm{pH}$ 10.8) and thereafter and each time after use it was stored in distilled water.
The various steps in measuring the $\zeta$ potential were: (a) wiping with dry filter, (b) cleaning in condensing vapor of carbon tetrachloride for $30 \mathrm{~min}$, (c) drying at $110^{\circ} \mathrm{C}$ for $30 \mathrm{~min}$, (d) rinsing with and storing in distilled water for $1 \mathrm{hr}$ in a weighing bottle, (e) pouring off the water and rinsing with the solution to be measured, (f) equilibrating in the latter for at least $20 \mathrm{hr}$.

$A d$ (iii). The wall of the hole in the cylinder was steamed for $1 \mathrm{hr}$ by pulling steam through the assembled central part AFA of Fig. 1, under reduced pressure, which was adjusted so as to let steam escape on the steam input side of AFA also. The PTFE rod, when its $\zeta$ potential was to be measured, was steamed at the same time by suspending it with a platinum wire holder in the steam input side of AFA.

\section{Experimental Procedure}

After the steaming procedure and cooling, the central part AFA was rinsed with the solution to be measured. The rod to be investigated was placed in the hole in $\mathrm{P}$ and after rinsing once more, the central part AFA was half-filled. Care was taken that no air remained in the hole. Air in the hole can be removed by moving the rod to and fro in the hole with the help of the glass bodies B and a magnet. The upper parts of the electrode assemblies were rinsed with the solution and joined with the central part. The apparatus was filled, starting with the central part, up to the upper sleeves, The voltage from the dc power supply was applied to the zinc electrodes. The potential difference across the plug was adjusted to a value such that the increase in temperature in the plug would be less than $3^{\circ} \mathrm{C}$ even when the solution with the highest conductivity in our experiments ( $\mathrm{pH}$ 2.2) was measured, in which case about $60 \mathrm{~V}$ was applied. In experiments with solutions of lower conductivity this potential difference was raised to about $200 \mathrm{~V}$. Previous measurements in $10^{-3} \mathrm{M} \mathrm{HCl}$ showed that the $\zeta$-potential values found were within $10 \%$ of the same value on varying the electric field from 40 to $130 \mathrm{~V} / \mathrm{cm}$, provided that the viscosity and dielectric constant values at the 


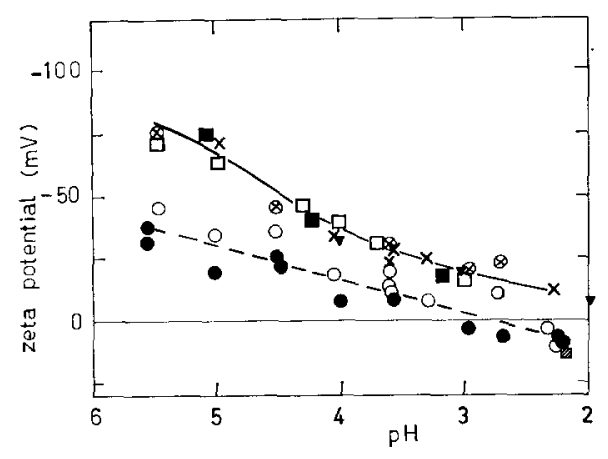

FIG. 2. The results obtained for the $\zeta$ potential of vitreous silica with $(\otimes)$ and without $(X)$ pretreatment steps c, d, e, f, and PTFE ( $O$, first system; $\bullet$, second system) as a function of $\mathrm{pH}$ with $10^{-3} M \mathrm{NaCl}$ background electrolyte. Quartz: $\mathbf{0}$, Jednačak et al. (2); $\nabla, \mathrm{Li}$ and De Bruyn (12). 10-3 $M \mathrm{KNO}_{3}\left(\mathrm{HNO}_{3}\right)$ : $\square$, Wiese et al. (1).

temperature $\left(24-31^{\circ} \mathrm{C}\right)$ prevailing in the plug were used in the calculation.

After the passing-by of the current for 30-60 $\mathrm{min}$, with automatical reversal of the current direction every $5 \mathrm{sec}$, the capillaries, with the filled vessels $\mathrm{V}$ clamped on the tubes $\mathrm{T}$, were put in place. The tubes $T$ were pushed in the stoppers until the capillaries were completely filled and were on the same level. Next, they were raised until the menisci were about $1 \mathrm{~cm}$ from the outer openings of the capillaries. Then, drops of detergent (RBS 25) were injected in the openings, so that air bells remained between the drops and the menisci. The tubes $T$ were pushed to and fro in the stopper to clean the outer $4 \mathrm{~cm}$ of the capillaries by the detergent. After this, the detergent was pushed out of the capillaries and the tubes $T$ were raised until the capillaries were on the same level with the menisci $2-3 \mathrm{~cm}$ from the openings, and the clamp $\mathrm{G}$ was applied.

The aligned capillaries were brought into a horizontal plane by means of the adjusting screws of the tripod. This was indicated by the difference of the times the meniscus required for traveling a given distance in both directions. After this adjustment, the times required for the meniscus in one capillary to travel a given distance were measured in a sequence of at least three pairs of reversals of the current direction. These measurements were repeated on the other capillary, after which the whole measuring procedure was repeated at least once more. Generally, the distance to be traversed was so chosen that $10-20 \mathrm{sec}$ was required for it. Depending on the $\zeta$ potentials and the applied potential difference, this distance was 0.10 to $2.00 \mathrm{~mm}$. We also noted: the polarity of the electrode to which the liquid in the hole was streaming, the total length of the liquid threads in the capillaries, the current strength for the calculation of the power dissipated in $P$, and the thermocouple electromotive force.

The application of a detergent in the capillaries may contaminate the liquid in the apparatus. However, without a detergent the electroosmotic displacement of the meniscus is usually retarded. The cleaning of the capillaries, using the procedure of Rose and Heins (10), as suggested by Dukhin and Derjaguin (11), takes considerable time and is only temporarily effective. Even when a detergent has been applied, the cleaning procedure usually has to be repeated after one or two complete sets of measurements. Before the apparatus is assembled for the next experiment, the upper parts of the electrode assemblies, which are not steamed as the part AFA, must be rinsed thoroughly with distilled water. With the procedure described, the application of a detergent is harmless. The measurements were performed in a room in which the temperature was fairly constant $\left( \pm 0.2^{\circ} \mathrm{C}\right)$ during any 1 day, but in a set of measurements the temperature varied from 20 to $23^{\circ} \mathrm{C}$. Combined with the increase in temperature owing to the dissipation of heat in the hole, the temperature of the liquid in the hole varied from 20 to $25^{\circ} \mathrm{C}$ in a set of measurements. Obviously, in the calculation of the $\zeta$ potential with [4], the viscosity and the dielectric constant of water at the temperature in the hole had to be used.

\section{RESULTS}

The results obtained for the $\zeta$ potential of vitreous silica in dependence on the $\mathrm{pH}$ at a 
constant background of $10^{-3} M \mathrm{NaCl}$ are given in Fig. 2, and those of synthetic sapphire $\left(\alpha-\mathrm{Al}_{2} \mathrm{O}_{3}\right.$ single crystal) in Fig. 3 . The results for the $\zeta$ potentials of both the PTFE cylinders with the PTFE rods belonging to them are also given in Fig. 2. The straight line along the PTFE data has been drawn by linear regression. The linear regression lines of each series separately are somewhat shifted with respect to this line. The $\zeta$ potentials of vitreous silica and of the sapphire have been calculated, in most cases, with the measured $\zeta$-potential values in the same solution.

\section{DISCUSSION}

The results obtained for vitreous silica show no systematic differences between the series with and without additional HF treatment in the purification procedure. They are down to $\mathrm{pH} \mathrm{3,} \mathrm{in} \mathrm{fair} \mathrm{agreement} \mathrm{with} \mathrm{the} \mathrm{results} \mathrm{of}$ Jednačak et al. (2) and Wiese et al. (1) in solutions acidified with $\mathrm{HNO}_{3}$ at a constant background of $10^{-3} M \mathrm{KNO}_{3}$. However, below $\mathrm{pH} 3$, some discrepancy seems to appear. Wiese $e t$ al. extrapolated their curves, measured at different constant background concentrations of $\mathrm{KNO}_{3}$, to an isoelectric point of $\mathrm{pH} 2.5 \pm 0.2$. The lowest $\mathrm{pH}$ at a background electrolyte concentration of $10^{-3} M \mathrm{NaCl}$ employed by Jednačak et al. in the case of vitreous silica is $\mathrm{pH} 3.2$. For quartz they reported a $\zeta=+13 \mathrm{mV}$ at $\mathrm{pH} 2.2$, giving an isoelectric point at $\mathrm{pH} 2.8$. According to these authors crushed quartz and vitreous silica are indistinguishable from one another within the experimental error. However, Li and De Bruyn's (12) measurements on quartz support the correctness of our results on vitreous silica. $\mathrm{Li}$ and De Bruyn's data at $10^{-3} \mathrm{M} \mathrm{NaCl}$ are also shown in Fig. 2, and one can see that their and our measurements are in good agreement. An ioselectric point of quartz lower than $\mathrm{pH} 2$ is also reported by Deju and Bhappu (13) and by Cases (14). Moreover, Jednačak et al.'s remark that a low signal-to-noise ratio prevented their measurements from being reproducible at $\mathrm{pH}$ values in the vicinity or beyond the point of zero

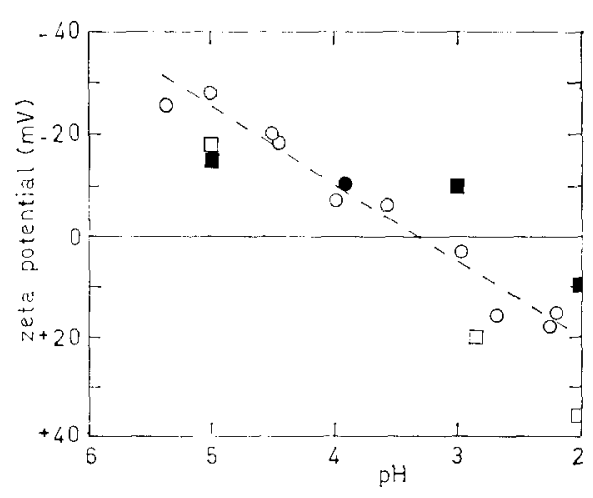

FiG. 3. The results obtained for the $\xi$ potential of synthetic sapphire as a function of $\mathrm{pH}$ with $10^{-3} \mathrm{M}$ $\mathrm{NaCl}$ background electrolyte. $\bullet$, Sample not treated with phosphoric acid; $\boldsymbol{\square}$, natural corundum; $\square$, $\alpha-\mathrm{Al}_{2} \mathrm{O}_{3}$ according to Van Schuylenborgh and Sänger (16).

potential throws some doubt on the reliability of their measurements at $\mathrm{pH}<3$.

In our opinion the measurements on vitreous silica prove the correctness of the method proposed, including the use of the formula for the axial-symmetrical position of the rod in the case of the nonaxial position. From the linear regression line in Fig. 3 (slope -15.2 $\mathrm{mV} / \mathrm{pH}$ ) the iep value $\mathrm{pH} 3.3$ is found for synthetic sapphire. This value is very different from the values recorded in the literature (15), with the exception of Van Schuylenborgh and Sänger's (16) values. This cannot be attributed to the phosphoric acid treatment since a measurement with the untreated sample gave the same result. Van Schuylenborgh and Sänger's electrophoresis data, converted into $\zeta$ potentials, for natural corundum and synthetic $\alpha-\mathrm{Al}_{2} \mathrm{O}_{3}$ in solutions acidified with $\mathrm{HCl}$ are shown in Fig. 3. These authors attributed their low iep values to the better crystallinity of their samples.

The isoelectric points referring to synthetic sapphire are $\mathrm{pH} 9.4$, reported by Modi and Fuerstenau (17), and $\mathrm{pH}$ 6.7, reported by Dobiáš et al. (18). To explain the difference between their and our iep values we consider their pretreatment of the synthetic sapphire boules. After crushing and sizing, most of the iron impurity introduced during crushing was 
removed with a hand magnet and the last traces were removed by treatment with hydrochloric acid $\left(60^{\circ} \mathrm{C}\right)$. The material was next washed with distilled water till free from chloride ion and then stored under conductivity water (Modi) or dried at $120^{\circ} \mathrm{C}$ (Dobiáš).

According to Somasundaran (19), however, comminution, screening, and other mechanical methods used in the preparation of particles of desired size deform the surface layer of as much as $300 \AA$ in thickness. Particles with such a disturbed surface layer are not likely to show the crystalline properties of the material (for data on $\mathrm{SiO}_{2}$, see Refs. $\left.(20,21)\right)$. It is well known that the presence of such layers yields a more reactive surface with increased solubility and increased surface hydration. Consequently a shift of the isoelectric point toward higher $\mathrm{pH}$ values is an observed result of mechanical surface disruption.

In Somasundaran's terminology Modi and Fuerstenau's iep of 9.4 refers to a hydroxylated surface, Dobiáš' iep of 6.7 to a dehydrated surface, and Van Schuylenborgh and Sänger's iep of 3.0 to a polymerized and partially dehydrated surface. Our iep represents that of a completely polymerized and dehydrated surface, as may be supposed to exist on a single crystal with an unconverted (nondisturbed) surface layer.

\section{APPENDIX}

When $(R-r) / R=\Delta R / r \ll 1$, the expansion of $\ln (\rho / r) / \ln (R / r)$ in [2] into a power series and the dropping of terms after the first power yield

$$
\begin{aligned}
v(\rho)=\frac{\epsilon_{0} \epsilon_{r}}{\eta} \frac{V}{L} & \left(\psi-\zeta_{1}\right) \\
& \quad+\frac{\epsilon_{0} \epsilon_{r}}{\eta} \frac{V}{L}\left(\zeta_{1}-\zeta_{2}\right) \frac{\rho-r}{R-r} .
\end{aligned}
$$

In this expression

$$
\frac{\epsilon_{0} \epsilon_{r}}{\eta} \frac{V}{L} \zeta_{1}=v_{1} \quad \text { and } \quad \frac{\epsilon_{0} \epsilon_{r}}{\eta} \frac{V}{L} \zeta_{2}=v_{2}
$$

can be interpreted as the velocities of the

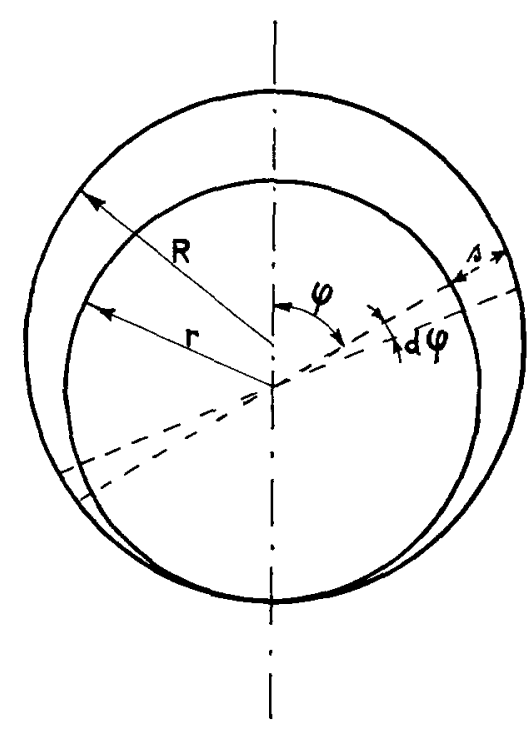

Figure A.

liquid at distances only a few times the DebyeHückel distance from both walls. Since $\psi$ is already practically zero at these distances from the walls, $\left[2^{\prime}\right]$ expresses the fact that the axial velocity of the liquid falls linearly in the radial direction from $v_{1}$ to $v_{2}$. Integration with the use of $\left[2^{\prime}\right]$ yields

$D=\pi\left(v_{1}+v_{2}\right) r \Delta R+\frac{1}{3} \pi\left(v_{1}+2 v_{2}\right)(\Delta R)^{2} . \quad\left[3^{\prime}\right]$

The last term in $\left[3^{\prime}\right]$ is negligible as long as $\Delta R \ll r$. Relation $\left[3^{\prime}\right]$ without this small term can also be obtained via the integration

$$
D=2 \int_{\phi=0}^{\phi=\pi} v_{m} d S=2 \pi v_{m} r \Delta R,
$$

in which $d S=(R-r) r d \phi$ is an infinitesimal sector of the ring between the two concentric circles of radii $r$ and $R . v_{m}$ is the axial velocity averaged over the radial direction: $v_{m}$ $=\left(v_{1}+v_{2}\right) / 2$. In the case of a system that consists of a rod resting on the wall of the canal (Fig. $A_{1}$ ), $D$ can be approximated in a similar way,

$D \approx 2 \int_{0}^{\pi} v_{m} s r d \phi$

$$
=2 v_{m}\left\{-r^{2} \pi+2 \operatorname{RrE}(k, \pi / 2)\right\}, \quad\left[3^{\prime \prime \prime}\right]
$$


in which $E(k, \pi / 2)$ is the complete elliptic integral of the second kind with $k=\Delta R / R$. The substitution $v_{m}=\left(v_{1}+v_{2}\right) / 2$ is again made for $v_{m}$, i.e., $v$ averaged over the distance $s$.

In our two cases (i) $R=1.2 \mathrm{~mm}, r=1.0$ $\mathrm{mm}$, and (ii) $R=0.80 \mathrm{~mm}, r=0.69 \mathrm{~mm}$, substitution of these values in $\left[3^{\prime \prime \prime}\right]$ and $\left[3^{\prime \prime}\right]$ yields $D\left[3^{\prime \prime \prime}\right] / D\left[3^{\prime \prime}\right]=0.96$ and 0.97 , respectively. Thus, the results of the approximate calculations for the systems with and without axial symmetry do not differ much. Since for axial symmetry the results of the exact and of the approximate calculations, using [3] and $\left[3^{\prime \prime}\right]$, respectively, are also much the same, we conclude that the value of $D$ calculated with [3] is a good approximation for the system without axial symmetry.

\section{REFERENCES}

1. Wiese, G. R., James, R. O., and Healy, T. W., Discuss. Faraday Soc. 52, 302 (1971).

2. JednaČak, J., Pravdić, V., and Haller, W., $J$. Colloid Interface Sci. 49, 16 (1974).

3. La Betre, JR., H. E., ANd Mlavsky, A. I., Mater. Res. Bull. 6, 571, 581 (1971).

4. Rutgers, A. J., AND De Suet, M., Trans. Faraday Soc. 41, 758 (1945).

5. Rutgers, A. J., And De Smet, M., Trans. Faraday Soc. 43, 102 (1947).
6. Rutgers, A. J., And De Smet, M., Trans. Faraday Soc. 48, 635 (1952).

7. Verwey, E. J. W., Rec. Trav. Chim. 60, 625 (1941).

8. Hensley, J. W., Long, A. O., ANd Willard, J. E., Ind. Eng. Chem. 41, 1415 (1949).

9. Quon, H. H., and Malanka, D. P., Mater. Res. Bull. 10, 349 (1975).

10. Rose, W., and Heins, R. W., J. Colloid Sci. 17, 39 (1962).

11. Dukhin, S. S., And Derjaguin, B. V., in "Surface and Colloid Science" (Egon Matijević, Ed.), Vol. 7, p. 81. Wiley, New York, 1974.

12. Li, H. C., And De Bruyn, P. L., Surface Sci. 5, 203 (1966).

13. Deju, R. A., ANd Bhappu, R. B., Trans. AIME:235, 329 (1966).

14. Cases, J. M., J. Chim. Phys. 66, 1602 (1969).

15. Parks, G. A., Chem. Rev. 65, 177 (1965).

16. Schuylenborgh, J. V., and Sängrer, A. M. H., Rec. Trav. Chimn. 68, 999 (1949).

17. Modi, H. J., and Fuerstenau, D. W., J. Phys. Chem. 61, 640 (1957).

18. Dobiáš, B., Spurny, J., And Freudlová, E., Collection Czech. Chem. Commun. 24, 3668 (1959).

19. Somasundaran, P., in "Clean Surfaces. Their Preparation and Characterization for Interfacial Studies" (G. Goldfinger, Ed.), p. 285. Dekker, New York, 1970.

20. Van Lier, J. A., De Bruyn, P. L., ANd OVerbeek, J. Th. G., J. Phys. Chem. 64, 1675 (1960).

21. Koopmans, K., and Rieck, G. D., Brit. $J . A p p l$. Phys. 16, 1913 (1965). 